ORIGINAL ARTICLE

\title{
Six year observational cohort study of the effect of carbon disulphide on brain MRI in rayon manufacturing workers
}

\author{
Y Nishiwaki, T Takebayashi, T O'Uchi, T Nomiyama, T Uemura, H Sakurai, K Omae
}

Occup Environ Med 2004;61:225-232. doi: 10.1136/oem.2002.006932

See end of article for authors' affiliations

Correspondence to:

Dr Y Nishiwaki

Department of Preventive

Medicine and Public

Health, School of

Medicine, Keio University,

35 Shinanomachi,

Shinjuku-ku, Tokyo

160-8582, Japan;

nisiwaki@sc.itc.keio.ac.jp

Accepted 23 May 2003
Aims: To clarify whether the current occupational exposure limit (OEL) for carbon disulphide $\left(\mathrm{CS}_{2}\right)$ is low enough to prevent the occurrence of adverse effects on the cerebrovascular system.

Methods: A total of 432 male workers exposed to $\mathrm{CS}_{2}$ and 402 male referent workers in 11 Japanese viscose rayon factories were studied at baseline; 750 of these were followed up. Brain MRI was performed at both baseline and follow up surveys. Changes in the number of hyperintense spots in T2 weighted images (HIS), which point to so-called "silent cerebral infarctions", were evaluated over six years. A total of 666 subjects (217 exposed, 125 ex-exposed, and 324 referent subjects) who twice received brain MRI were subjected to analysis. Mean duration of exposure to the end of the study was 19.6 years for the exposed workers. The geometric mean $\mathrm{CS}_{2}(\mathrm{ppm})$ and TTCA $(\mathrm{mg} / \mathrm{g}$ creatinine) concentrations for the past six years were 4.9 and 1.6 for all exposed workers, 5.8 and 1.9 for spinning/refining workers, and 2.7 and 0.9 for other exposed workers, respectively.

Results: Exposed subjects showed a significantly higher risk for an increase in the number of HIS over six years. Odds ratios adjusted for possible confounders in the exposed and ex-exposed workers were 2.27 (95\% Cl 1.37 to 3.76$)$ and $1.33(95 \% \mathrm{Cl} 0.70$ to 2.54$)$, respectively. No exposure-response relations were observed in a number of analyses among the exposed workers.

Conclusions: Exposure to $\mathrm{CS}_{2}$ under the current Japanese OEL, $10 \mathrm{ppm}$, might increase the number of HIS in brain MRI. However, results should be interpreted with caution.
$\mathrm{T}$ here have been many reports on increases in risks for arteriosclerosis, ${ }^{12}$ coronary heart disease, ${ }^{3-7}$ and retinal microaneurysm ${ }^{8-12}$ due to exposure to carbon disulphide $\left(\mathrm{CS}_{2}\right)$. However, significant attention has not been paid to the effect of exposure to $\mathrm{CS}_{2}$ on cerebral vessels. One report ${ }^{13}$ describing a high incidence of cerebrovascular diseases by an epidemiological approach could not preclude the possibility of chance or confounding, and another report ${ }^{14}$ found that exposure to $\mathrm{CS}_{2}$ had no effect on cerebral vessels. On the other hand, a report on postmortem results indicated that cerebrovascular impairment was responsible for encephalopathy due to $\mathrm{CS}_{2}$ exposure. ${ }^{15}$ There have been a few reports $^{16-20}$ presenting brain images of workers exposed to $\mathrm{CS}_{2}$, but a comprehensive epidemiological study of the relation between exposure to $\mathrm{CS}_{2}$ and brain images has not been carried out.

At present, $10 \mathrm{ppm}$ is recommended as the occupational exposure limit (OEL) by the Japan Society for Occupational Health $(\mathrm{JSOH})^{21}$ and as the threshold limits value (TLV) of the American Conference of Governmental Industrial Hygienists (ACGIH) ${ }^{22}$ However, it is undetermined whether the current exposure level can sufficiently prevent health impairment. Thus, we planned a prospective cohort study of the workers in 11 Japanese viscose rayon manufacturing factories, and performed a baseline survey in 1992 and 1993 and a follow up survey in 1998 and 1999. This is a comprehensive investigation to detect the effects of exposure to $\mathrm{CS}_{2}$ on the vascular system and nervous system.

In this article, we present an evaluation of the subclinical effects of exposure to $\mathrm{CS}_{2}$ on the cerebrovascular system using magnetic resonance imaging (MRI) of the brain.

\section{SUBJECTS AND METHODS}

\section{Study population and study profile}

The design of the cohort study and details of the follow up have been described elsewhere. ${ }^{23-25}$ Briefly, the study subjects consisted of 432 male workers exposed to $\mathrm{CS}_{2}$ and 402 male referent workers in 11 Japanese viscose rayon factories. None of the subjects had any medical history of cerebrovascular and cardiovascular diseases, including medically treated hypertension at baseline, determined by checking companies' medical records and through a self administered questionnaire. Figure 1 shows the study profile. A comprehensive evaluation of subjects' health, including cerebrovascular, cardiovascular, ophthalmological, neurological, neurobehavioural, and endocrinological aspects was conducted at a baseline survey (1992-93), and at a follow up survey (199899). Of 834 workers, 750 (391 CS $\mathrm{CS}_{2}$ exposed and 359 referent) participated in the follow up survey. Eighty four subjects (41 $(9.5 \%)$ from the $\mathrm{CS}_{2}$ exposed and $43(10.7 \%)$ from the referent group) who were lost to follow up included 56 retirements, 24 transfers within the company, and four deaths (one from the $\mathrm{CS}_{2}$ exposed and three from the referent group).

We checked the medical records of the companies at retirement and confirmed that there were no workers who retired due to health problems. The four subjects who died during the study period died from causes other than cerebrovascular disease.

There were no major differences in baseline characteristics between subjects who had followed up and those who had not within the exposed and referent groups. Among the $\mathrm{CS}_{2}$ exposed workers, 251 remained to be exposed to $\mathrm{CS}_{2}$ until the end of the observation period (exposed workers), and 140 workers had their exposure truncated because four factories

Abbreviations: BMI, body mass index; HDL, high density lipoprotein; $\mathrm{HDL}-\mathrm{C}$, high density lipoprotein cholesterol; HIS, hyperintense spots; MRI, magnetic resonance imaging; OEL, occupational exposure limit; SBP, systolic blood pressure; TLV, threshold limit value; TTCA,

2-thiothiazolidine-4-carboxylic acid 


\section{Main messages}

- This six year cohort study is, we believe, the first comprehensive epidemiological study to assess the relation between occupational exposure to $\mathrm{CS}_{2}$ and subclinical findings in brain MRI in rayon manufacturing workers.

- Exposure to $\mathrm{CS}_{2}$ under the current Japanese occupational exposure limit, $10 \mathrm{ppm}$, might increase the number of hyperintense spots in $\mathrm{T} 2$ weighted images in this population.

discontinued production of rayon fibres around 1994-95 for economic reasons (ex-exposed workers). The mean and median periods from the cessation of exposure to the follow up survey in the ex-exposed subjects were 4.0 and 4.1 years (range 0.8-6.9 years), respectively. After summarising the subjects' job records, some of the ex-exposed and referent workers were reclassified as exposed workers since they were still being exposed to $\mathrm{CS}_{2}$ when they worked near rayon production areas, and some referent workers were excluded from the study subjects because they had histories of $\mathrm{CS}_{2}$ exposure for 1-8 years before the observation period. ${ }^{25}$ Therefore, $744(89.2 \%)$ subjects were subject to analysis for the whole cohort study, which consisted of 259 exposed, 133 ex-exposed, and 352 referent subjects. From 744 subjects, 666 subjects who received a brain MRI at both the baseline and follow up surveys were subjected to MRI evaluation and analysis for this study, which includes 217 exposed, 125 exexposed, and 324 referent subjects. Seventy eight subjects did not have brain MRI twice: 42 exposed (16.2\%), eight exexposed $(6.0 \%)$, and 28 referent $(8.0 \%)$ subjects. Of these, 35 exposed workers at one factory did not have MRI because there was no MRI equipment near the factory site. Other excluded workers did not have MRI because of work schedule conflict. No major differences in characteristics were detected between workers with MRI and those without MRI within the exposed, ex-exposed, and referent groups. During the observation period, two exposed and two referent workers developed non-fatal stroke. As two workers were not followed up and two other workers did not have MRI at the follow up survey, they were excluded from the study population.

Table 1 shows the baseline characteristics of each group. The exposed workers were younger, had lower body mass index (BMI), and drank and smoked more than the exexposed and the referent workers. The proportion of subjects with higher education and percentage of shift work varied among the groups.

Assessment of the exposure to $\mathrm{CS}_{2}$ has been described elsewhere. ${ }^{25}$ Briefly, $\mathrm{CS}_{2}$ concentrations in the workers' breathing zone were measured twice a year since the spring of 1993 during the study period with a Parkin-Elmer diffusive sampler tube. The level of 2-thiothiazolidine-4-carboxylic acid (TTCA), a metabolite of $\mathrm{CS}_{2}$, in urine was also determined twice a year beginning in the autumn of 1992 as a biological monitoring parameter. Individual exposure level was represented by the arithmetic mean of TTCA and $\mathrm{CS}_{2}$ concentration for six years. The geometric mean TTCA concentrations for all exposed workers, the spinning or refining workers, and other exposed workers were 1.60, 1.89, and $0.93 \mathrm{mg} / \mathrm{g}$ creatinine, respectively. The geometric mean TTCA concentrations in the 1 st, 2nd, 3rd, and 4th quartiles classified by mean TTCA concentration in six years, namely the $\mathrm{H}, \mathrm{MH}, \mathrm{ML}$, and $\mathrm{L}$ groups, were $3.53,2.02,1.35$, and $0.68 \mathrm{mg} / \mathrm{g}$ creatinine, respectively. The geometric mean TTCA

\section{Policy implications}

- The results should be interpreted cautiously because of the lack of an exposure-response relation.

- Until these result are confirmed by further studies, reassessment of the current Japanese occupational exposure limit of $10 \mathrm{ppm}$ should not be based only on the results of this study.

concentrations in 1992 in the 1st, 2nd, 3rd, and 4th quartiles classified by TTCA concentration in 1992 alone, namely the $\mathrm{H}^{\prime}, \mathrm{MH}^{\prime}, \mathrm{ML}^{\prime}$, and $\mathrm{L}^{\prime}$ groups, were $7.21,3.94,2.04$, and $0.58 \mathrm{mg} / \mathrm{g}$ creatinine, respectively. The geometric mean $\mathrm{CS}_{2}$ concentrations in the workers' breathing zone for all exposed workers, the spinning or refining workers, and other exposed workers were 4.87, 5.81, and $2.74 \mathrm{ppm}$, respectively (table 2). These concentrations were much lower than the OEL recommended by JSOH and the TLV by ACGIH. The geometric mean $\mathrm{CS}_{2}$ concentrations in the $\mathrm{H}, \mathrm{MH}, \mathrm{ML}$, and L groups were $8.10,6.20,4.54$, and 2.47 ppm, respectively.

\section{Evaluation of brain MRI}

Brain MRI was performed twice at the baseline and the follow up surveys at eight hospitals near the factories surveyed with at least 0.5 tesla equipment, except for 0.2 tesla in one hospital. In six years, the MRI equipment was upgraded in four hospitals and was unchanged in four hospitals. We used T2 weighted images at the transverse slices and $\mathrm{Tl}$ weighted images at coronary slices with 8-10 mm thickness. In order to minimise errors due to differences among hospitals and imaging systems, a few subjects were imaged as trials and the images were sent to one neuroradiologist, one of the authors (TO). The neuroradiologist checked the quality of the images and instructed MRI technicians at each hospital to make conditions uniform if possible.

After the follow up survey, 666 pairs of MRI films (baseline and follow up) were sent to the neuroradiologist for evaluation. In order to avoid inter-observer error, one neuroradiologist assessed all films alone. He was under blind condition including exposure status. The neuroradiologist displayed a pair of films on the view box together at the same time, and compared the baseline and follow up films. He evaluated (a) hyperintense spots in $\mathrm{T} 2$ weighted images (HIS) in the cerebrum, brain stem, and cerebellum, and (b) atrophy of the cerebrum, for the baseline and follow up films.

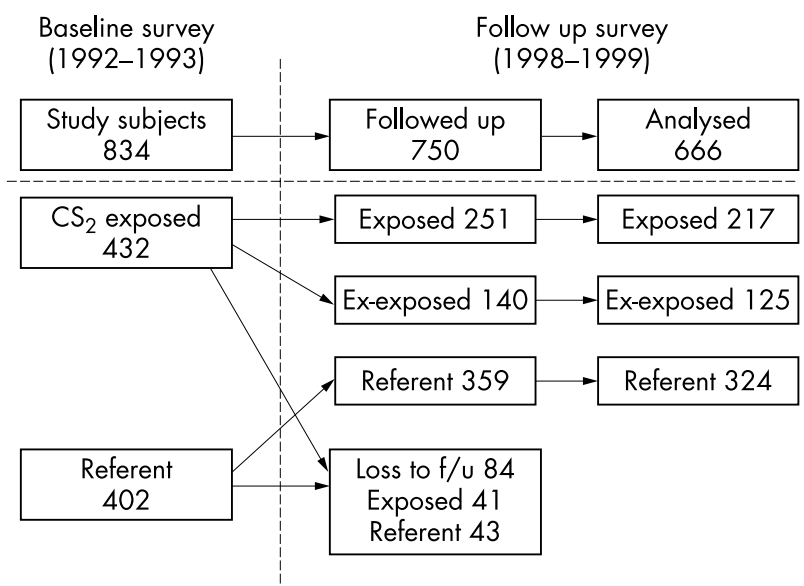

Figure 1 Study profile and results of follow up. 
Table 1 Characteristics of the study population at baseline

\begin{tabular}{|c|c|c|c|c|}
\hline & Exposed & Ex-exposed & Reference & p value* \\
\hline Number & 217 & 125 & 324 & \\
\hline Age $(y) \dagger$ & $35.4(7.6)$ & $36.8(7.9)$ & $35.8(9.1)$ & 0.30 \\
\hline \multicolumn{5}{|l|}{ Age distribution (y) } \\
\hline$<30$ & $66(30.4 \%)$ & $35(28.0 \%)$ & 106 (32.7\%) & \multirow[t]{3}{*}{$<0.05$} \\
\hline $30-39$ & $75(34.6 \%)$ & $31(24.8 \%)$ & $64(19.8 \%)$ & \\
\hline$\geqslant 40$ & $76(35.0 \%)$ & $59(47.2 \%)$ & $154(47.5 \%)$ & \\
\hline Height $(\mathrm{cm}) \dagger$ & $168.8(6.5)$ & $168.4(5.5)$ & $168.4(6.1)$ & 0.72 \\
\hline Weight $(\mathrm{kg}) \dagger$ & $63.1(7.5)$ & $64.4(9.0)$ & $64.2(8.6)$ & 0.25 \\
\hline BMI $\left(\mathrm{kg} / \mathrm{m}^{2}\right) \dagger$ & $22.1(2.4)$ & $22.7(2.8)$ & $22.6(2.8)$ & 0.08 \\
\hline Habitual drinker & $150(69.1 \%)$ & $74(59.2 \%)$ & $219(67.6 \%)$ & 0.15 \\
\hline \multicolumn{5}{|l|}{ Alcohol consumption (g ethanol/day) } \\
\hline 0 & $67(30.9 \%)$ & $51(40.8 \%)$ & 105 (32.4\%) & \multirow[t]{3}{*}{0.05} \\
\hline $1-50$ & 113 (52.1\%) & $65(52.0 \%)$ & $181(55.9 \%)$ & \\
\hline$>50$ & $37(17.1 \%)$ & $9(7.2 \%)$ & $38(11.7 \%)$ & \\
\hline Current smoker & $153(70.5 \%)$ & $86(68.8 \%)$ & $195(60.2 \%)$ & $<0.05$ \\
\hline \multicolumn{5}{|l|}{ Pack-years } \\
\hline 0 & $64(29.5 \%)$ & $39(31.2 \%)$ & $129(39.8 \%)$ & \multirow[t]{3}{*}{0.09} \\
\hline $1-20$ & $96(44.2 \%)$ & $53(42.4 \%)$ & $112(34.6 \%)$ & \\
\hline$>20$ & $57(26.3 \%)$ & $33(26.4 \%)$ & $83(25.6 \%)$ & \\
\hline Education (percentage of senior high or higher) & 133 (61.3\%) & $79(63.2 \%)$ & 234 (75.2\%) & $<0.05$ \\
\hline Shift work (\% shift workers) & 183 (84.3\%) & $86(68.8 \%)$ & $288(88.9 \%)$ & $<0.01$ \\
\hline SBP $(\mathrm{mm} \mathrm{Hg}) \dagger$ & $121.2(12.2)$ & $119.9(12.2)$ & $120.1(11.6)$ & 0.54 \\
\hline $\mathrm{DBP}(\mathrm{mm} \mathrm{Hg}) \dagger$ & $71.3(10.7)$ & $69.7(9.2)$ & $70.1(10.7)$ & 0.34 \\
\hline Total cholesterol $(\mathrm{mg} / \mathrm{dll}) \dagger$ & $186.9(31.6)$ & $186.3(32.1)$ & $190.2(35.8)$ & 0.41 \\
\hline $\mathrm{HDL}$ cholesterol $(\mathrm{mg} / \mathrm{dll}) \dagger$ & $53.0(13.4)$ & $53.5(14.3)$ & $51.5(13.3)$ & 0.28 \\
\hline
\end{tabular}

The diagnostic criteria for HIS were those recommended by the study subgroup on diagnostic criteria, pathogenesis, and management for asymptomatic cerebrovascular diseases. ${ }^{26}$ HIS point to so-called silent cerebral infarction. However, recent experiences ${ }^{27}{ }^{28}$ suggest that these may include myelin pallor, gliosis, and dilated perivascular space with arteriosclerotic changes. Thus, we used the expression "HIS" instead of "silent cerebral infarction" in the present study. The neuroradiologist checked all slices on the MRI film and counted the number of HIS. To reduce a chance of misclassification due to subtle change in number of HIS, classification into four categories- "none," "a few," "about 10 ," and "a lot" - rather than number of HIS was used. Finally, to assess the intra-individual change over six years, "increased" or "unchanged" was globally judged by the neuroradiologist comparing the baseline and follow up MRI films. There was a range of possible HIS numbers within each category. For instance, both 8 HIS and 12 HIS were classified into "about $10^{\prime \prime}$. The neuroradiologist had the ability to assess some cases as "increased" by global judgement, even if the classifications into the four listed categories were the same at both baseline and follow up.

\section{Statistical analysis}

First, prevalence of HIS and atrophy both at baseline and follow up were compared among exposed, ex-exposed, and referent groups by $\chi^{2}$ test or Fisher's exact method. The proportion of globally judged increases in HIS was then compared among groups. To assess the exposureresponse relation, exposed workers were divided into two groups according to the work category at baseline, namely, the spinning or refining workers and other exposed workers. The spinning or refining workers were predicted to be exposed to higher concentrations of $\mathrm{CS}_{2}$ than other exposed workers. Twelve exposed workers had been transferred to different $\mathrm{CS}_{2}$ jobs during the study period, and allocated to a new job category if job transfer occurred more than one year before the follow up survey. Exclusion of such workers did not show much change of the result by separate analysis. The exposed workers were further

Table 2 Assessment of exposure to $\mathrm{CS}_{2}$

\begin{tabular}{|c|c|c|c|c|c|c|c|c|c|}
\hline & \multicolumn{3}{|c|}{$\begin{array}{l}\text { Duration of exposure to follow up } \\
\text { survey }(y)\end{array}$} & \multicolumn{3}{|c|}{$\begin{array}{l}\mathrm{CS}_{2} \text { concentration during the study } \\
\text { period* }(\mathrm{ppm})\end{array}$} & \multicolumn{3}{|c|}{$\begin{array}{l}\text { TCA concentration during the stud } y \\
\text { period }^{*}+(\mathrm{mg} / \mathrm{g} \text { creatinine) }\end{array}$} \\
\hline & 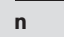 & Mean & SD & $\bar{n}$ & Mean & SD & $n$ & Mean & SD \\
\hline All exposed & 217 & 19.6 & 8.0 & $216^{\circ}$ & 4.87 & 1.81 & $216^{9}$ & 1.60 & 1.91 \\
\hline Spinning or refining & 165 & 19.9 & 8.1 & 165 & 5.81 & 1.64 & 165 & 1.89 & 1.80 \\
\hline Other than spinning or refined & 52 & 18.7 & 7.7 & 51 & 2.74 & 1.68 & 51 & 0.93 & 1.71 \\
\hline $\mathrm{H} \ddagger$ & 54 & 18.3 & 7.9 & 54 & 8.10 & 1.27 & 54 & 3.53 & 1.31 \\
\hline $\mathrm{MH}$ & 53 & 21.1 & 8.0 & 53 & 6.20 & 1.30 & 53 & 2.02 & 1.13 \\
\hline$M L$ & 55 & 20.0 & 7.4 & 55 & 4.54 & 1.54 & 55 & 1.35 & 1.15 \\
\hline $\mathrm{L}$ & 55 & 19.0 & 8.7 & 54 & 2.47 & 1.76 & 54 & 0.68 & 1.46 \\
\hline$H^{\prime} \S$ & 54 & 19.9 & 8.5 & - & - & - & 54 & 7.21 & 1.22 \\
\hline $\mathrm{MH}^{\prime}$ & 54 & 20.6 & 7.4 & - & - & - & 54 & 3.94 & 1.21 \\
\hline$M L^{\prime}$ & 54 & 19.5 & 7.7 & - & - & - & 54 & 2.04 & 1.24 \\
\hline $\mathrm{L}^{\prime}$ & 55 & 18.5 & 8.6 & - & - & - & 53 & 0.58 & 1.86 \\
\hline
\end{tabular}

*Geometric mean and GSD.

†TTCA concentration for $\mathrm{H}^{\prime}, \mathrm{MH}^{\prime}, \mathrm{ML}^{\prime}$, and $\mathrm{L}^{\prime}$ groups shows the concentration in 1992 alone.

$\ddagger$ Quartile classified by mean TTCA concentration over 6 years.

§Quartile classified by TTCA concentration in 1992.

TThere was one missing value. 
divided into quartiles according to mean TTCA concentration in six years and quartiles according to mean TTCA concentration in 1992.

To control for the possible confounders, multiple logistic regression analysis was performed. Independent variables included in the age adjusted logistic model were index of exposure and age at baseline (continuous variable). For the multivariate adjusted model, smoking $(0,1-20,>20$ packyears), alcohol intake (0, 1-50, >50 g ethanol/day), BMI, education level (at least high school, or less), shift work (yes or no), systolic blood pressure (SBP) and high density lipoprotein cholesterol (HDL-C) at baseline were added to exposure and age as covariates. If necessary, other models which did not include SBP and/or HDL-C were also constructed. Age and exposure duration to the end of the study were highly correlated, so we could not construct a valid logistic model including these two variables due to colinearity. Thus, stratified analysis by age and exposure duration was used. In the strict analysis, at least one category increase was defined as "increased" using four categories described previously.

Sixteen of 125 (12.8\%) ex-exposed workers and 13 of 324 $(4.0 \%)$ referent workers were exposed to solvents other than $\mathrm{CS}_{2}$ during the study period, but none of those solvents showed any health risks with regard to the cerebrovascular and cardiovascular systems. Thus, we did not exclude such workers from the analysis. For the trend analysis, we performed logistic regression using exposure parameter as a continuous variable.

The SAS software package (Cary, NC) was used for all statistical analysis.

\section{RESULTS}

Table 3 shows the prevalence of HIS and cerebral atrophy at the baseline and the follow up surveys. When the cut-off point was set at "a few or more" in the cerebrum, for example, the prevalence of HIS in exposed, ex-exposed, and referent workers was $36.9 \%, 36.0 \%$, and $37.3 \%$ at baseline and $39.6 \%, 40.0 \%$, and $38.9 \%$ at follow up, respectively, but these differences were not statistically significant. In crosssectional analysis of both the baseline and follow up surveys, no relations between exposure to $\mathrm{CS}_{2}$ and prevalence of HIS were observed. If we look at changes in category over six years, however, 26 exposed (19 in cerebrum, seven in brain stem, and one in cerebellum), 13 ex-exposed ( 12 in cerebrum and one in brain stem), and 20 referent (all in cerebrum) subjects showed at least one category increase. In contrast, five exposed (all in cerebrum), two ex-exposed (one in cerebrum and one in brain stem), and three referent (one in cerebrum and two in brain stem) subjects showed one category reduction from "a few" to "none". The global judgement by the neuroradiologist for these 10 subjects was "unchanged" in each. The prevalence of cerebral atrophy at the baseline and follow up surveys was not different among the groups.

The global judgements for "increased" or "unchanged" in number of HIS over six years were then compared among groups. Figure 2 shows a case assessed as "increased" by the neuroradiologist. Proportions of subjects assessed as "increased" in the exposed, ex-exposed, and referent groups were $24.0 \%, 15.2 \%$, and $12.4 \%$, respectively (table 4 ). The odds ratio adjusted for age in logistic regression analysis, in which the dependent variable was "increased" or "unchanged" in number of HIS over six years, was 2.56 (95\% CI 1.59 to 4.10 ) in the exposed group and 1.24 (95\% CI 0.68 to 2.27 ) in the ex-exposed group. The multivariate adjusted odds ratio in the exposed group (adjusted OR 2.27, $95 \%$ CI 1.37 to 3.76 ) remained significantly higher compared to the referent group. Age was a significant risk factor for an increase in number of HIS, separate from exposure to $\mathrm{CS}_{2}$.

Of subjects who were globally assessed as "increased", 26 exposed (12.0\%), 13 ex-exposed (10.4\%), and 20 referent $(6.2 \%)$ subjects showed at least one category increase. When this criterion was applied, the multivariate adjusted odds ratio showed marginally significant result in the exposed group (adjusted OR 1.89, 95\% CI 0.97 to 3.68) compared to the referent group.

If the exposed workers were divided by their work category, the multivariate adjusted odds ratio in the spinning or refining workers (adjusted OR 2.36, 95\% CI 1.37 to 4.08 ) was significantly higher than that of the referent workers. The odds ratio in the other exposed workers (adjusted OR $2.02,95 \%$ CI 0.92 to 4.44 ) did not show a significant result. When "at least one category increase" was used for analysis, the multivariate adjusted odds ratio did not reach statistical significance even in the spinning or refining workers.

The multivariate adjusted odds ratios were significantly higher in the $\mathrm{H}$ (adjusted OR 2.28, 95\% CI 1.01 to 5.17), ML (adjusted OR 3.22, 95\% CI 1.56 to 6.63 ), and L (adjusted OR $2.63,95 \%$ CI 1.27 to 5.52 ) groups according to mean TTCA concentrations over six years. Whichever criteria for increase in HIS were applied, no exposure-response relations with mean TTCA concentrations were observed over six years. The multivariate adjusted odds ratios were significantly higher in the $\mathrm{H}^{\prime}$ (adjusted OR 2.35, 95\% CI 1.07 to 5.16), $\mathrm{MH}^{\prime}$ (adjusted OR 2.78, 95\% CI 1.34 to 5.75), and ML' (adjusted OR 2.10 , 95\% CI 0.96 to 4.59 ) groups according to TTCA' concentrations in 1992 alone, but test for trend did not show the significant result.

Table 5 shows the result of stratified analysis by age group. Proportions of subjects assessed as "increased" seemed to increase with age strata in the exposed, ex-exposed, and referent groups. This suggests increasing age is a risk factor for HIS. Within each age strata, higher proportion of subjects assessed as "increased" was observed in the exposed group compared to the referent group. After adjustment for the possible confounders, a significantly higher odds ratio was observed only among subjects $<30$ years old at baseline. This might reflect that the workers in the $<30$ years old age group were exposed to the higher $\mathrm{CS}_{2}$ and TTCA than workers in other age groups. The geometric mean TTCA concentrations of the exposed workers in the $<30,30-39$, and $\geqslant 40$ years old age groups were $1.87,1.63$, and $1.36 \mathrm{mg} / \mathrm{g}$ creatinine, respectively. The geometric mean concentration of $\mathrm{CS}_{2}$ were $6.14,4.48$, and $4.30 \mathrm{ppm}$, respectively. Only two subjects were assessed as "increased" in the referent group whose age group was $<30$. This might also account for such a high OR (11.7) in this age strata to some extent. Table 5 also shows the result after stratifying by the exposure duration to the end of the study in each age stratum among exposed workers. No clear trend with the exposure duration was observed. Adjusted odds ratios in the exposed group were significantly higher than the referent group in both subjects with HIS negative results (adjusted OR 3.38, 95\% CI 1.06 to 10.76 ) and subjects with HIS positive results (adjusted OR $2.68,95 \%$ CI 1.39 to 5.16 ) at the baseline survey.

\section{DISCUSSION}

A few studies have described the association between exposure to $\mathrm{CS}_{2}$ and brain MRI findings, and reported that prevalent findings were multiple lesions in the basal ganglia and corona radiata on $\mathrm{T} 2$ weighted images ${ }^{17} 18$ or white matter hyperintensity and lacunar infarcts on T2 weighted images. ${ }^{20}$ However, these studies were case series in which the study subjects were patients with $\mathrm{CS}_{2}$ poisoning. The present study provides the first opportunity to assess the relation between occupational exposure to $\mathrm{CS}_{2}$ and 


\begin{tabular}{|c|c|c|c|c|}
\hline Survey and cut off point & $\begin{array}{l}\text { Exposed }(n=217) \text {, } \\
\text { no. }(\%)\end{array}$ & $\begin{array}{l}\text { Ex-exposed }(n=125) \text {, } \\
\text { no. }(\%)\end{array}$ & $\begin{array}{l}\text { Reference }(n=324) \text {, } \\
\text { no. }(\%)\end{array}$ & p value* \\
\hline \multicolumn{5}{|l|}{ HIS in cerebrum } \\
\hline \multicolumn{5}{|l|}{ Baseline survey } \\
\hline None & $137(63.1)$ & $80(64.0)$ & $203(62.7)$ & \multirow{4}{*}{0.96} \\
\hline A few & $60(27.7)$ & $36(28.8)$ & $91(28.1)$ & \\
\hline About 10 & $17(7.8)$ & $7(5.6)$ & $22(6.8)$ & \\
\hline A lot & $3(1.4)$ & $2(1.6)$ & $8(2.5)$ & \\
\hline \multicolumn{5}{|l|}{ Follow up survey } \\
\hline None & $131(60.4)$ & $75(60.0)$ & $198(61.1)$ & \multirow[t]{4}{*}{0.99} \\
\hline A few & $61(28.1)$ & $35(28.0)$ & $87(26.9)$ & \\
\hline About 10 & $16(7.4)$ & $8(6.4)$ & $24(7.4)$ & \\
\hline A lot & $9(4.1)$ & $7(5.6)$ & $15(4.6)$ & \\
\hline \multicolumn{5}{|l|}{ HIS in brain stem } \\
\hline \multicolumn{5}{|l|}{ Baseline survey } \\
\hline None & $210(96.8)$ & $116(92.8)$ & $309(95.4)$ & \multirow[t]{4}{*}{0.24} \\
\hline A few & $7(3.2)$ & $9(7.2)$ & $15(4.6)$ & \\
\hline About 10 & 0 & 0 & 0 & \\
\hline A lot & 0 & 0 & 0 & \\
\hline \multicolumn{5}{|l|}{ Follow up survey } \\
\hline None & $203(93.6)$ & $116(92.8)$ & $309(95.4)$ & \multirow{4}{*}{0.49} \\
\hline A few & $14(6.4)$ & $9(7.2)$ & $15(4.6)$ & \\
\hline About 10 & 0 & 0 & 0 & \\
\hline A lot & 0 & 0 & 0 & \\
\hline \multicolumn{5}{|l|}{ HIS in cerebellum } \\
\hline Baseline survey & & & & \\
\hline None & $216(99.5)$ & $123(98.4)$ & $323(99.7)$ & \multirow{4}{*}{0.11} \\
\hline A few & $1(0.5)$ & $2(1.6)$ & & \\
\hline About 10 & 0 & 0 & $1(0.3)$ & \\
\hline A lot & 0 & 0 & 0 & \\
\hline \multicolumn{5}{|l|}{ Follow up survey } \\
\hline None & $215(99.1)$ & $123(98.4)$ & $323(99.7)$ & \multirow[t]{4}{*}{0.09} \\
\hline A few & $2(0.9)$ & $2(1.6)$ & & \\
\hline About 10 & 0 & 0 & $1(0.3)$ & \\
\hline A lot & 0 & 0 & 0 & \\
\hline \multicolumn{5}{|l|}{ Cerebral atrophy } \\
\hline Baseline survey & & & & \\
\hline Atrophy $(-)$ & $208(95.8)$ & 118 (94.4) & 304 (93.8) & \multirow[t]{2}{*}{0.59} \\
\hline Atrophy $(+)$ & $9(4.2)$ & $7(5.6)$ & $20(6.2)$ & \\
\hline \multicolumn{5}{|l|}{ Follow up survey } \\
\hline Atrophy $(-)$ & $201(92.6)$ & 118 (94.4) & $299(92.3)$ & \multirow{2}{*}{0.73} \\
\hline Atrophy (+) & $16(7.4)$ & $7(5.6)$ & $25(7.7)$ & \\
\hline
\end{tabular}

subclinical findings in brain MRI in rayon manufacturing workers. As described in the previous report in detail, ${ }^{23} 25$ our study is a prospective six year cohort study in which study subjects were recruited from all of the rayon manufacturing factories in Japan. Our study has several advantages, including having proper referent workers, a high follow up rate, and a detailed assessment of exposure during the study period.
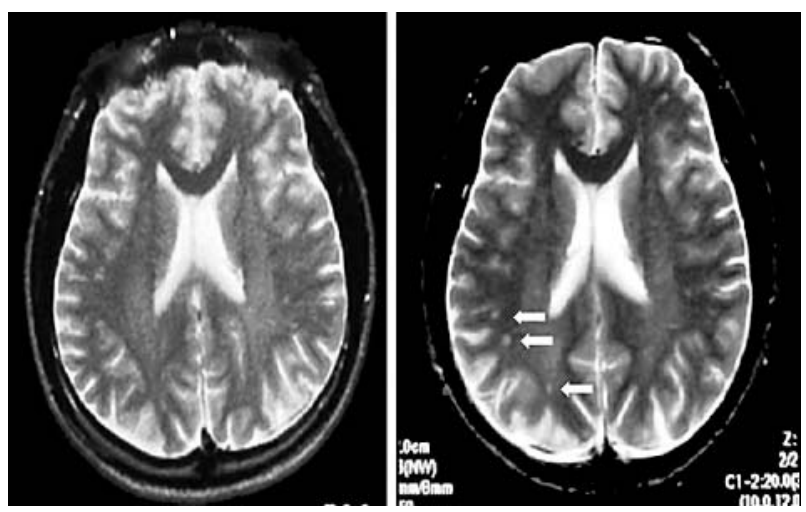

Figure 2 A representative case which was assessed as "increased" in number of hyperintense spots on T2 weighted images over six years. The left brain MRI image is at baseline, and the right image at follow up. Small arrows indicate hyperintense spots.
In this study, the workers exposed to $\mathrm{CS}_{2}$ with a mean exposure duration of 19.6 years to the end of the study showed a significantly higher risk of an increase in number of HIS over six years, even after adjustment for the possible confounders. Even when "at least one category increase" was used as the criterion for the analysis, the exposed workers were likely to have an increase of HIS, although it was marginally significant. In the ex-exposed workers, there was no significant increase of HIS compared to the referent workers. If the observed association between the exposure to $\mathrm{CS}_{2}$ and increase in number of HIS was causal and workers included in this study had been exposed for some years prior to the baseline survey, a higher prevalence of HIS in the exposed group should have been observed in the crosssectional analysis at baseline. However, such a difference was not observed. This might be explained if a higher percentage of workers had left their job due to health effects caused by exposure to $\mathrm{CS}_{2}$ in the exposed group than referent group before the baseline survey. As we could not obtain such information from the companies, we failed to determine the reason for this unexpected result.

This is the first study to evaluate the relation between occupational exposure to $\mathrm{CS}_{2}$ and subclinical findings in brain MRI in rayon manufacturing workers as far as we are aware, hence there is no consistent epidemiological study. However, a previous study in Italy did show agreement with the present study. Vigliani ${ }^{15}$ showed by postmortem examination of the patients with encephalopathy due to exposure 
Table 4 Intra-individual changes in hyperintense spots on T2 weighted images over six years

\begin{tabular}{|c|c|c|c|c|c|c|}
\hline & $\begin{array}{l}\text { Proportion of } \\
\text { "increased" }\end{array}$ & $\begin{array}{l}\text { Age adjusted OR } \\
(95 \% \mathrm{Cl})^{*}\end{array}$ & $\begin{array}{l}\text { Multivariate } \\
\text { adjusted OR } \\
(95 \% \mathrm{Cl}) \dagger\end{array}$ & $\begin{array}{l}\text { Proportion of "at } \\
\text { least } 1 \text { category } \\
\text { increased" }\end{array}$ & $\begin{array}{l}\text { Age adjusted OR } \\
(95 \% \mathrm{Cl})^{*}\end{array}$ & $\begin{array}{l}\text { Multivariate } \\
\text { adjusted OR } \\
(95 \% \mathrm{Cl}) \dagger\end{array}$ \\
\hline Reference & $40 / 324(12.4 \%)$ & 1 & 1 & $20 / 324(6.2 \%)$ & 1 & 1 \\
\hline Ex-exposed & $19 / 125(15.2 \%)$ & 1.24 (0.68 to 2.27$)$ & $1.33(0.70$ to 2.54$)$ & $13 / 125(10.4 \%)$ & $1.74(0.83$ to 3.64$)$ & $1.62(0.74$ to 3.59$)$ \\
\hline Exposed & $52 / 217(24.0 \%)$ & $2.56(1.59$ to 4.10$)$ & 2.27 (1.37 to 3.76$)$ & $26 / 217(12.0 \%)$ & 2.29 (1.23 to 4.28$)$ & 1.89 (0.97 to 3.68$)$ \\
\hline \multicolumn{7}{|c|}{ ו } \\
\hline Other than spinning or refining & $12 / 52(23.1 \%)$ & 2.20 (1.05 to 4.63$)$ & 2.02 (0.92 to 4.44$)$ & $6 / 52(11.5 \%)$ & $2.02(0.70$ to 5.09$)$ & $1.89(0.68$ to 5.27$)$ \\
\hline Spinning or refining & $40 / 165(24.2 \%)$ & 2.69 (1.62 to 4.46$)$ & 2.36 (1.37 to 4.08 ) & $20 / 165(12.1 \%)$ & 2.39 (1.23 to 4.66$)$ & 1.89 (0.92 to 3.87$)$ \\
\hline \multicolumn{7}{|l|}{$\begin{array}{l}\text { Quartile by } 6 \text { year mean TTCA } \\
\text { (1992-98) }\end{array}$} \\
\hline $\mathrm{L}$ & $15 / 55(27.3 \%)$ & 2.78 (1.38 to 5.62$)$ & 2.63 (1.27 to 5.52$)$ & $5 / 55(9.1 \%)$ & $1.53(0.54$ to 4.31$)$ & $1.29(0.44$ to 3.76$)$ \\
\hline ML & $17 / 55(30.9 \%)$ & $3.52(1.78$ to 6.97$)$ & 3.22 ( 1.56 to 6.63$)$ & $9 / 55(16.4 \%)$ & $3.22(1.36$ to 7.61$)$ & $2.69(1.06$ to 6.81$)$ \\
\hline $\mathrm{MH}$ & $9 / 53(17.0 \%)$ & 1.48 (0.66 to 3.32$)$ & $1.19(0.51$ to 2.81$)$ & $6 / 53(11.3 \%)$ & $1.98(0.75$ to 5.26$)$ & $1.64(0.58$ to 4.62$)$ \\
\hline $\mathrm{H}$ & $11 / 54(20.4 \%)$ & 2.71 (1.24 to 5.92$)$ & $2.28(1.01$ to 5.17$)$ & $6 / 54(11.1 \%)$ & 2.71 (1.00 to 7.36$)$ & 2.15 (0.76 to 6.12$)$ \\
\hline \multicolumn{7}{|l|}{ Quartile by TTCA in 1992} \\
\hline $\mathrm{L}^{\prime}$ & $11 / 55(20.0 \%)$ & 1.95 (0.92 to 4.17$)$ & 1.85 (0.83 to 4.12$)$ & $5 / 55(9.1 \%)$ & 1.64 (0.58 to 4.64$)$ & $1.45(0.49$ to 4.27$)$ \\
\hline$M L^{\prime}$ & $13 / 54(24.1 \%)$ & 2.57 (1.24 to 5.36$)$ & 2.10 (0.96 to 4.59$)$ & $6 / 54(11.1 \%)$ & 2.10 (0.79 to 5.58$)$ & $1.56(0.56$ to 4.40$)$ \\
\hline $\mathrm{MH}^{\prime}$ & $16 / 54(29.6 \%)$ & 3.36 (1.68 to 6.73$)$ & $2.78(1.34$ to 5.75$)$ & $11 / 54(20.4 \%)$ & 4.31 (1.90 to 9.79$)$ & 3.31 (1.38 to 7.94$)$ \\
\hline $\mathrm{H}^{\prime}$ & $12 / 54(22.2 \%)$ & $2.44(1.15$ to 5.17$)$ & $2.35(1.07$ to 5.16$)$ & $4 / 54(7.4 \%)$ & $1.39(0.45$ to 4.31$)$ & 1.25 (0.38 to 4.07$)$ \\
\hline
\end{tabular}

*Exposure variable and age were included in the logistic regression model

†Adding to variables in the age adjusted model, smoking $(0,1-20,>20$ pack-years), alcohol intake $(0,1-50,>50 \mathrm{~g}$ ethanol/day), BMl, education level (at least high school, or less), shift work (yes or no), systolic blood pressure, and HDL cholesterol.

to $\mathrm{CS}_{2}$ that sclerosis of the small vessels in the brain was the cause. The results from the epidemiological studies defining cerebrovascular events as the end points were conflicting. Pepllonska and colleagues in Poland ${ }^{29}$ observed a significantly increased risk of deaths from cerebrovascular diseases (SMR 208) in viscose factory workers. Liss and Finkelstein in Canada $^{13}$ showed increases in mortality from cerebrovascular disease in viscose rayon manufacturing workers exposed to $\mathrm{CS}_{2}$. The proportional mortality ratio (PMR) of cerebrovascular diseases was 115, and that in those exposed to high concentrations of $\mathrm{CS}_{2}$ was 207. However, the authors suggested the observed increase in proportional mortality from strokes might represent a chance finding. MacMahon and Monson $^{14}$ have reported that SMR for cerebrovascular diseases was 108 (95\% CI 90 to 128), and its relation to exposure to $\mathrm{CS}_{2}$ was uncertain because of the absence of a dose-response relation. As reported in the previous paper, a higher incidence of retinal microaneurysm and ischaemic electrocardiogram findings (defined as Minnesota codes I,
$\mathrm{IV}_{1-3}, \mathrm{~V}_{1-3}$ at rest and after the load or receiving treatment for ischaemia) was observed in the exposed workers in this cohort. ${ }^{30}$ However, it is unknown whether these arteriosclerotic changes have the same mechanism as an increase in number of HIS. Although several hypotheses have been proposed, including changes in lipid metabolism, changes in fibrinolytic activity, advanced lipid infiltration, acceleration of atherosclerosis, and subclinical hypothyroidism, ${ }^{18}$ the mechanism of vasculopathy due to $\mathrm{CS}_{2}$ is still unknown.

In order to assess the exposure-response relation, several classifications were used in this study. First, the exposed workers were divided into the spinning or refining and other workers according to their work category. This seemed to be a rough classification; on the other hand it might be less likely to introduce misclassification of exposure. The multivariate adjusted odds ratio was slightly higher in the spinning or refining workers exposed to higher concentration of $\mathrm{CS}_{2}$ than that in the other exposed workers. However, this difference was small and not statistically significant. The exposed

Table 5 Stratified analysis with age at baseline; MRI findings at baseline and exposure duration for changes in hyperintense spots on $\mathrm{T} 2$ weighted images over six years

\begin{tabular}{|c|c|c|c|c|c|c|c|}
\hline & \multicolumn{6}{|c|}{ Proportion of "increased" } & \multirow{4}{*}{$\begin{array}{l}\text { Test for trend } \\
\text { by exposure } \\
\text { duration* }\end{array}$} \\
\hline & \multirow[b]{3}{*}{ Reference } & \multirow[b]{3}{*}{ Ex-exposed } & \multicolumn{4}{|l|}{ Exposed } & \\
\hline & & & \multicolumn{4}{|c|}{ Exposed duration to follow up survey in the exposed group } & \\
\hline & & & All & $\leqslant 20 y$ & $10-19 y$ & $<10 y$ & \\
\hline $\begin{array}{l}\text { Age at baseline (y) } \\
<30\end{array}$ & $2 / 106(1.9 \%)$ & $\begin{array}{l}2 / 35(5.7 \%) \\
509(0.62-41.96)\end{array}$ & $\begin{array}{l}11 / 66(16.7 \%) \\
1172(2.27-6039)\end{array}$ & - & $7 / 35$ (20.0\%) & $4 / 31(12.9 \%)$ & $p=0.44$ \\
\hline $30-39$ & $\begin{array}{l}8 / 64(12.5 \%) \\
1.00\end{array}$ & $\begin{array}{l}7 / 31(22.6 \%) \\
1.95(0.56-6.86)\end{array}$ & $\begin{array}{l}17 / 75(22.7 \%) \\
1.73(0.61-4.89)\end{array}$ & $13 / 47(27.7 \%)$ & $3 / 25(12.0 \%)$ & $1 / 3(33.3 \%)$ & $p=0.31$ \\
\hline$\geqslant 40$ & $\begin{array}{l}30 / 154(19.5 \%) \\
1.00\end{array}$ & $\begin{array}{l}10 / 59(17.0 \%) \\
0.91(0.38-2.20)\end{array}$ & $\begin{array}{l}24 / 76(31.6 \%) \\
1.69(0.85-3.35)\end{array}$ & $20 / 62(32.3 \%)$ & $2 / 10(20.0 \%)$ & $2 / 4(50.0 \%)$ & $p=0.88$ \\
\hline $\begin{array}{l}\text { MRI findings at baseline } \\
\text { Hyperintense spot negative }\end{array}$ & $\begin{array}{l}6 / 211(3.0 \%) \\
1.00\end{array}$ & $\begin{array}{l}6 / 77(7.8 \%) \\
2.84(0.77-10.52)\end{array}$ & $\begin{array}{l}11 / 135(8.2 \%) \\
3.38(1.06-10.76)\end{array}$ & $7 / 59$ (11.9\%) & $2 / 51(3.9 \%)$ & $2 / 25(8.0 \%)$ & $p=0.34$ \\
\hline Hyperintense spot positive & $\begin{array}{l}34 / 123(27.6 \%) \\
1.00\end{array}$ & $\begin{array}{l}13 / 48(27.1 \%) \\
1.16(0.52-2.59)\end{array}$ & $\begin{array}{l}41 / 82(50.0 \%) \\
2.68(1.39-5.16)\end{array}$ & $26 / 50(52.0 \%)$ & $10 / 19(52.6 \%)$ & $5 / 13(38.5 \%)$ & $p=0.46$ \\
\hline
\end{tabular}

Results expressed as proportion of "increased"; with adjusted odds ratios (95\% Cl) underneath.

In the logistic regression model, exposure: smoking $(0,1-20,>20$ pack-years $)$, alcohol intake $(0,1-50,>50 \mathrm{~g}$ ethanol/day).

$\mathrm{BMI}$, education level (at least high school, or less), shift work (yes or no), systolic blood pressure, and HDL cholesterol were included.

When evaluating for the subjects with negative hyperintense spots results and the subjects with positive hyperintense spots results at baseline, age was added into the models.

*Trend by exposure duration to the follow up survey. 
subjects were then divided into quartiles according to urinary TTCA concentration over six years, and no exposure-response relation was observed. Although accurate estimation of exposure is difficult because of the lack of past data about $\mathrm{CS}_{2}$ concentrations, exposure level would have been higher in the past. The intervening effects of research have improved the environment since 1992. ${ }^{25}$ Thus, mean TTCA concentrations over six years could reflect the most recent exposure but could not reflect higher exposure concentrations in the past. Therefore, using urinary TTCA concentrations in 1992 alone, which might better reflect exposure prior to the observation period, the subjects were again classified into quartiles for evaluation. Although significant increases in the odds ratios were seen in the upper three groups $\left(\mathrm{H}^{\prime}, \mathrm{MH}^{\prime}\right.$, and $\left.\mathrm{ML}^{\prime}\right)$ when classifying according to urinary TTCA concentrations in 1992 alone, there was no statistically significant trend. Exposure duration to the end of the study based on the company job record was used as one of surrogate measures of exposure. No clear trend of proportion of subjects assessed as "increased" with exposure duration was observed, although this was based on a relatively small sample. Although some previous studies ${ }^{16}{ }^{19}$ reported a cerebral atrophy on computed tomography in workers occupationally exposed to $\mathrm{CS}_{2}$, our study confirmed no relation between cerebral atrophy on brain MRI and exposure to $\mathrm{CS}_{2}$.

Several limitations of this study should be discussed. Firstly, no exposure data were available before the start of follow up in 1992. To interpret the results of this study, the key issue is whether current exposure levels caused increases in number of HIS or not. An alternative explanation could be possible - that is, arteriosclerotic change in cerebral vessels caused by higher exposure to $\mathrm{CS}_{2}$ in the past might manifest themselves by aging. As we have no information on exposure level in the past, it is not easy to determine to what extent the current exposure to $\mathrm{CS}_{2}$ accounts for the increased risk of HIS over six years. As presented in table 5, the proportion of "increased" in the exposed workers whose exposure duration to the end of the study was less than 10 years in the $<30$ year old group was $12.9 \%$. Average exposure duration prior to baseline, and the geometric mean TTCA and $\mathrm{CS}_{2}$ concentrations during the study period in this group were 2.5 years, $1.83 \mathrm{mg} / \mathrm{g}$ creatinine, and $6.45 \mathrm{ppm}$, respectively. Since mean age of this group (24.0 years) was comparable with that of referent workers (24.1 years) in the $<30$ year old group, we compared proportions between them. There was a significant difference $\left(\chi^{2}=6.95, \mathrm{p}<0.01\right)$ between the two (exposed $12.9 \%$ versus referent $1.9 \%$ ). This suggests that the recent exposure levels might contribute to the increased risk of increases in number of HIS over six years to some extent.

Secondly, potential biases should be taken into consideration. From the original cohort, 84 subjects were lost to follow up and another 84 subjects were excluded from the MRI evaluation and the analysis. Of these, there were no workers who retired due to health problems and none refused MRI examination due to their health condition. In fact, there were no major differences in baseline characteristics between subjects who had been followed up and those who had not, and between subjects with MRI and those without. Because of the substantial number of exclusions and different exclusion rates among groups, however, selection bias could not be completely eliminated.

Although efforts to minimise errors due to the differences among hospitals and imaging systems were made, this study would be subject to an information bias if such differences were associated with the exposure status. However, since exposed, ex-exposed, and referent workers in each factory were imaged in the same hospital, differences among hospitals and imaging systems might not cause an information bias. Furthermore, MRI equipment was changed in four hospitals. For the same reason, such changes of MRI equipment were less likely to introduce an information bias. We also conducted multiple logistic analyses among subjects who were imaged in the hospitals where the MRI equipment remained unchanged. The adjusted odds ratio was 1.84 (95\% CI 1.00 to 3.38 ) in the exposed workers and 1.13 (95\% CI 0.52 to 2.46 ) in the ex-exposed workers, which was significantly higher in the exposed workers compared to the reference. MRI equipment in one hospital was 0.2 tesla, whereas others were 0.5 tesla. However, exclusion of one hospital with 0.2 tesla equipment did not change the results. In order to prevent differential misclassification, we made the neuroradiologist blind to the information, including exposure status. Although it is occasionally difficult to distinguish HIS from dilated perivascular spaces, the misclassification due to such a difficulty could be non-differential. Ten subjects showed one category reduction from "a few" to "none". Since this is not likely biologically plausible, this was probably due to the slicing position and/or artefact. For balance, it is sensible to expect that at least the same number of subjects showed one category increase even though there were no true changes. Because the neuroradiologist evaluated MRI films under blind condition, any such misclassification would be nondifferential. However, if the misclassification had occurred differently among groups, the effect caused by 10 misclassifications would not be small.

To control for possible confounders, stratification by age and the multivariate analyses were used. If SBP or HDL-C were on the causal pathway between exposure to $\mathrm{CS}_{2}$ and an increase in number of HIS, it would not be appropriate to include these variables into models in the multivariate analyses. We also constructed the models in which SBP and/or HDL were excluded, and confirmed that the adjusted odds ratios were not so different from those in the models that included SBP and HDL-C. However, it was difficult to eliminate residual confounding or the effect of other unknown confounders completely.

In addition to the limitations of this study discussed above, another issue is the prognostic significance of HIS. The recent cohort study with four years' follow up clearly showed that the presence of silent cerebral infarcts on MRI, which corresponds to HIS, was an independent predictor of the risk of symptomatic stroke in older individuals without a clinical history of stroke. ${ }^{31}$ However, since this result could not be directly applicable to relatively younger populations like the subjects in this study, it has to be interpreted with caution.

In conclusion, this prospective cohort study showed that workers exposed to $\mathrm{CS}_{2}$ were likely to have an increase in the number of hyperintense spots on $\mathrm{T} 2$ weighted images of brain MRI. However, the results should be interpreted cautiously due to lack of an exposure-response relation and several potential limitations of the study. Until these results are confirmed by further studies, reassessment of the current Japanese occupational exposure limit of $10 \mathrm{ppm}$ should not be based only on the result of this study. A more comprehensive understanding and judgement based on studies including different outcomes is needed.

\section{ACKNOWLEDGEMENTS}

We thank Dr S Momoshima (Department of Diagnostic Radiology, School of Medicine, Keio University) for useful advice. For their cordial cooperation, we thank the members of the Subcommittee for Carbon Disulphide in the Committee of the Occupational Health, the Japan Chemical Fibre Association, and the staff of the divisions of occupational health and environmental control in the 11 rayon 
factories surveyed. This study was supported by a grant from the Japan Chemical Fibre Association.

\section{Authors' affiliations}

Y Nishiwaki, T Takebayashi, T Nomiyama, T Uemura, H Sakurai,

K Omae, Department of Preventive Medicine and Public Health, School of Medicine, Keio University, Tokyo, Japan

T O'Uchi, Kemeda General Hospital, Japan

H Sakurai, Occupational Health Research and Development Center, Japan Industrial Safety and Health Association, Japan

\section{REFERENCES}

1 Wronska-Nofer T, Szendzikowski S, Obrebska-Parke M. Influence of chronic carbon disulphide intoxication on the development of experimental atherosclerosis in rats. Br J Ind Med 1980;37:387-93.

2 Lewis JG, Graham DG, Valentine WM, et al. Exposure of C57BL/6 mice to carbon disulfide induces early lesions of atherosclerosis and enhances arterial fatty deposits induced by a high fat diet. Toxicol Sci 1999;49:124-32

3 Hernberg S, Tolonen M, Nurminen M. Eight-year follow-up of viscose rayon workers exposed to carbon disulfide. Scand J Work Environ Health 1976:2:27-30

4 Tolonen $\mathrm{M}$, Hernberg S, Nordman $\mathrm{CH}$, et al. Angina pectoris, electrocardiographic findings and blood pressure in Finnish and Japanese workers exposed to carbon disulfide. Int Arch Occup Environ Health 1976;37:249-64.

5 Tolonen M, Nurminen M, Hernberg S. Ten-year coronary mortality of workers exposed to carbon disulfide. Scand J Work Environ Health 1979;5:109-14.

6 Nurminen M, Mutanen P, Tolonen M, et al. Quantitated effects of carbon disulfide exposure, elevated blood pressure and aging on coronary mortality. Am J Epidemiol 1982;115:107-18.

7 Sweetnam PM, Taylor SW, Elwood PC. Exposure to carbon disulphide and ischaemic heart disease in a viscose rayon factory. $\mathrm{Br} J$ Ind Med 1987; $44: 220-7$

8 Hotta R, Sugimoto K, Goto S. Retinopathia sulfocarbonica and its natural history [in Japanese]. Nippon Ganka Gakkai Zasshi 1972;76:1561-6.

9 Sugimoto K, Goto S, Hotta R. Studies on chronic carbon disulfide poisoning. A 5 -year follow-up study on retinopathy due to carbon disulfide. Int Arch Occup Environ Health 1976;37:233-48.

10 Sugimoto K, Goto S, Kanda S, et al. Studies on angiopathy due to carbon disulfide. Retinopathy and index of exposure dosages. Scand J Work Environ Health 1978;4:151-8.

11 De Rouck A, De Laey JJ, Van Hoorne M, et al. Chronic carbon disulphide poisoning: a 4 year follow-up study of the ophthalmological signs. Int Ophthalmol 1986:9:17-27.

12 Vanhoorne M, De Rouck A, Bacquer D. Epidemiological study of the systemic ophthalmological effects of carbon disulfide. Arch Environ Health 1996;51:181-8.
13 Liss GM Finkelstein MM. Mortality among workers exposed to carbon disulfide. Arch Environ Health 1996;51:193-200.

14 MacMahon B, Monson RR. Mortality in the US rayon industry. J Occup Med 1988:30:698-705.

15 Vigliani EC. Carbon disulphide poisoning in viscose rayon factories. $\mathrm{Br} J$ Ind Med 1954;11:235-44.

16 Sugimura K, Kabashima K, Tatetsu S, et al. Computed tomography in chronic carbon disulfide poisoning [in Japanese]. No To Shinkei 1979:31:1245-53.

17 Huang CC, Chu CC, Chen RS, et al. Chronic carbon disulfide encephalopathy. Eur Neurol 1996;36:364-8.

18 Huang CC, Chu CC, Chu NS, et al. Carbon disulfide vasculopathy: a small vessel disease. Cerebrovasc Dis 2001;11:245-50.

19 Chrostek Maj J, Czeczotko B. The evaluation of the health state of the workers occupationally exposed to low concentration of carbon disulphide $\left(\mathrm{CS}_{2}\right)$. Part two: The complex way of the examination of the central nervous system (CNS). Przegl Lek 1995;52:252-6.

20 Cha JH, Kim SS, Han H, et al. Brain MRI findings of carbon disulfide poisoning. Korean J Radiol 2002;3:158-62.

21 The Japan Society for Occupational Health. Recommendation of occupational exposure limits (2001-2002). J Occup Health 2001:208-23.

22 American Conference of Governmental Industrial Hygienists. Documentation of the threshold limit values and biological exposure indices, 6th edn. Cincinnati: ACGIH, 1985-1986.

23 Omae K, Takebayashi T, Nomiyama T, et al. Cross sectional observation of the effects of carbon disulphide on arteriosclerosis in rayon manufacturing workers. Occup Environ Med 1998;55:468-72.

24 Takebayashi T, Omae K, Ishizuka C, et al. Cross sectional observation of the effects of carbon disulphide on the nervous system, endocrine system, and subjective symptoms in rayon manufacturing workers. Occup Environ Med 1998;55:473-9.

25 Takebayashi T, Nishiwaki Y, Nomiyama T, et al. Lack of relationship between occupational exposure to carbon disulfide and endocrine dysfunction: a sixyear cohort study of Japanese rayon workers. J Occup Health 2003;45:111-18

26 Sawada T, Taneda J, Okamoto K, et al. Study on diagnostic criteria for asymptomatic cerebrovascular diseases [in Japanese]. Jpn J Stroke 1997; 19:489-93.

27 Takao M, Koto A, Tanahashi N, et al. Pathologic findings of silent hyperintense white matter lesions on MRI. J Neurol Sci 1999;167:127-31.

28 Takao M, Koto A, Tanahashi N, et al. Pathologic findings of silent, small hyperintense foci in the basal ganglia and thalamus on MRI. Neurology 1999;52:666-8

29 Pepllonska B, Sobala W, Szeszenia-Dabrowska N. Mortality pattern in the cohort of workers exposed to carbon disulfide. Int J Occup Med Environ Health $2001 ; 14: 267-74$.

30 Takebayashi T, Nishiwaki Y, Uemura T, et al. A six-year follow-up study of the subclinical effects of carbon disulfide exposure on the cardiovascular system. Occup Environ Med In press.

31 Bernick C, Kuller L, Dulberg C, et al. Silent MRI infarcts and the risk of future stroke: the cardiovascular health study. Neurology 2001;57:1222-9. 